\title{
ERRATUM
}

\section{Erratum to: Synthesis and characterization of lanthanide- doped sodium holmium fluoride nanoparticles for potential application in photothermal therapy}

\author{
Kaushik DAS ${ }^{1}$, G. A. KUMAR ${ }^{2,3,4}$, Leonardo MIRANDOLA ${ }^{5}$, Maurizio CHIRIVA-INTERNATI $^{5,6,7}$, \\ and Jharna CHAUDHURI (禺) $)^{1,7}$ \\ 1 Department of Mechanical Engineering, Texas Tech University, Lubbock, TX 79409, USA \\ 2 Department of Physics and Astronomy, University of Texas at San Antonio, San Antonio, TX 78249, USA \\ 3 Department of Atomic and Molecular Physics, Manipal University, Manipal 576104, Karnataka, India \\ 4 Department of Natural and Physical Sciences, Northwest Vista College, 3535 N Ellison Dr, San Antonio, TX 78251, USA \\ 5 Kiromic BioPharma, 7707 Fannin St., Suite 140, Houston, TX 77054, USA \\ 6 Department of Gastroenterology, Hepatology and Nutrition, University of Texas MD Anderson Cancer Center, Houston, TX 77030, USA \\ 7 Department of Mechanical and Materials Engineering, PO Box 751, Portland State University, Portland, OR 97207-0751, USA
}

(C) Higher Education Press 2020

Erratum to: Front. Mater. Sci. 2019, 13(4): 389-398

DOI: $10.1007 / \mathrm{s} 11706-019-0480-1$

The authors did not realize that the presentations of some TEM images were incorrect. The versions of such figures and the corresponding text should be changed as follows.

- Page 393, the paragraph "TEM images in Figs. 2(a) and 2(b) show silica- and gold-decorated $\mathrm{NaHoF}_{4}: \mathrm{Yb}^{3+}, \mathrm{Er}^{3+} \mathrm{NPs}$ with an average size of 20-30 nm and they are well dispersed. Gold NPs of smaller size of $8-10 \mathrm{~nm}$ and darker in contrast can be clearly seen to be attached on the surface of the silica shell and the silica coating can be seen at the edge as a line. Figures 2(b) and 2(c) show HRTEM images with the $d$ spacing of gold NPs as $0.238 \mathrm{~nm}$ corresponding to the (1 111 ) plane and the $d$ spacing of $\mathrm{NaHoF}_{4}: \mathrm{Yb}^{3+}, \mathrm{Er}^{3+} \mathrm{NPs}$ as $0.316 \mathrm{~nm}$ corresponding to the (1 110$)$ plane, respectively. This again confirms the presence of gold and single crystalline nature of gold and $\mathrm{NaHoF}_{4}: \mathrm{Yb}^{3+}, \mathrm{Er}^{3+}$. The SAED pattern in Fig. 2(d) shows gold diffraction rings (2.363 $\AA$ ) of randomly oriented particles and $\mathrm{NaHoF}_{4}: \mathrm{Yb}^{3+}, \mathrm{Er}^{3+}$ diffraction rings $(2.921 \AA)$ indicating random distribution of NPs." should read "The TEM image in Fig. 2(a) show silica- and gold-decorated $\mathrm{NaHoF}_{4}: \mathrm{Yb}^{3+}, \mathrm{Er}^{3+} \mathrm{NPs}$ with an average size of $20-30 \mathrm{~nm}$ and they are well dispersed. Gold NPs of smaller size of $8-10 \mathrm{~nm}$ and darker in contrast can be clearly seen to be attached on the surface of the silica shell and the silica coating can be seen at the edge as a line. Figures 2(b) and 2(c) show HRTEM images with the $d$ spacing of gold NPs as $0.238 \mathrm{~nm}$ corresponding to the $\left(\begin{array}{lll}1 & 1 & 1\end{array}\right)$ plane and the $d$ spacing of $\mathrm{NaHoF}_{4}: \mathrm{Yb}^{3+}, \mathrm{Er}^{3+} \mathrm{NPs}$ as $0.521 \mathrm{~nm}$ corresponding to the $\left(\begin{array}{lll}1 & 0 & 0\end{array}\right)$ plane. This again confirms the presence of gold and single crystalline nature of gold and $\mathrm{NaHoF}_{4}: \mathrm{Yb}^{3+}, \mathrm{Er}^{3+}$. The SAED patterns in Fig. 2(d) show $\mathrm{NaHoF}_{4}: \mathrm{Yb}^{3+}, \mathrm{Er}^{3+}$ diffraction rings $(2.919,2.273,1.796$ and 1.689 A corresponding to (lllll 101$),\left(\begin{array}{lll}1 & 1 & 1\end{array}\right),\left(\begin{array}{lll}0 & 0 & 2\end{array}\right)$ and $\left(\begin{array}{lll}1 & 0 & 2\end{array}\right)$ planes, respectively) indicating random distribution of NPs."

Received May 28, 2020

E-mail: jharna.chaudhuri@ttu.edu 
- Page 393, the corrected Fig. 2 and corresponding legend is given below.

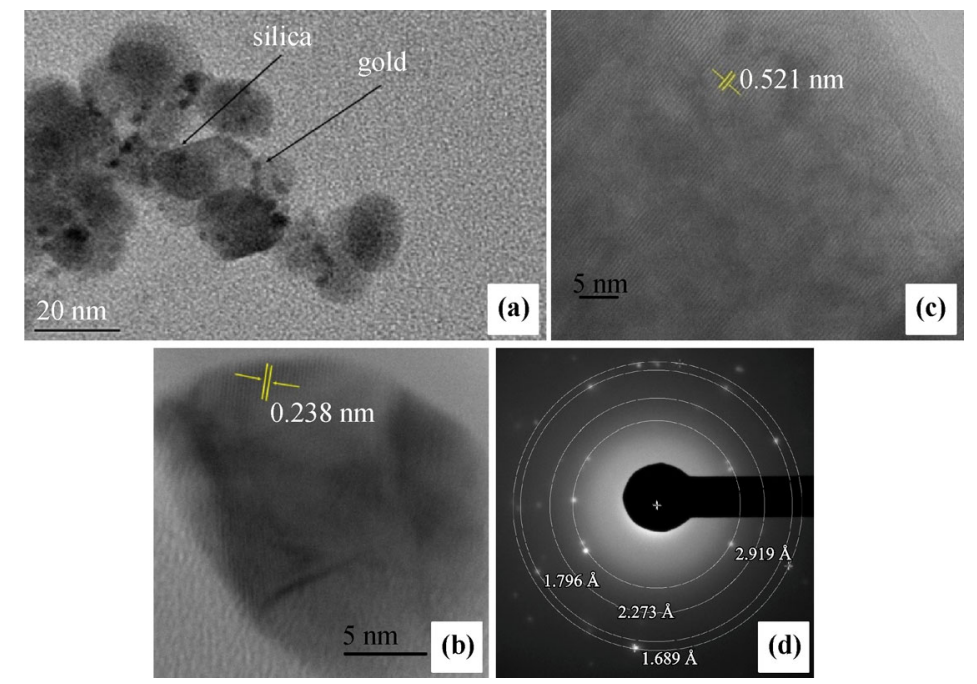

Fig. 2 (a) TEM image of gold-decorated silica-coated $\mathrm{NaHoF}_{4}: \mathrm{Yb}^{3+}, \mathrm{Er}^{3+} \mathrm{NPs}$ with the silica coating and gold particles marked. (b) HRTEM image showing the $d$ spacing of gold. (c) HRTEM image showing the $d$ spacing of $\mathrm{NaHoF}_{4}: \mathrm{Yb}^{3+}, \mathrm{Er}^{3+} \mathrm{NPs}^{\text {(d) }}$ SAED patterns of $\mathrm{NaHoF}_{4}: \mathrm{Yb}^{3+}, \mathrm{Er}^{3+} \mathrm{NPs}$.

- $\quad$ Page 394, the paragraph “The SEM image in Fig. 4 displays the morphology of $\mathrm{NaHoF}_{4}: \mathrm{Yb}^{3+}, \mathrm{Er}^{3+} @ \mathrm{PPy}$ samples. The SEM picture shows that the PPy has a distinct cauliflower-like or tumor-like structure. TEM image in Fig. 5(a) shows $\mathrm{NaHoF}_{4}: \mathrm{Yb}^{3+}, \mathrm{Er}^{3+} \mathrm{NPs}$ with an average size of $30 \mathrm{~nm}$ and they are well dispersed. The PPy coating of approximately 3 $\mathrm{nm}$ in thickness is attached on the surface of the NPs which is shown by the presence of darker shades on larger disc like nanoplates. This is also shown as a circular edge on the NPs. The interplanar spacing of $\mathrm{NaHoF}_{4}: \mathrm{Yb}^{3+}, \mathrm{Er}^{3+} \mathrm{NPs}_{\text {of }}$ $0.316 \mathrm{~nm}$ corresponds to the $\left(\begin{array}{lll}1 & 1 & 0\end{array}\right)$ plane as shown in Fig. 5(b) and confirms the excellent single crystalline nature of $\mathrm{NaHoF}_{4}: \mathrm{Yb}^{3+}, \mathrm{Er}^{3+} \mathrm{NPs}$." should read "The SEM image in Fig. 4 displays the morphology of $\mathrm{NaHoF}_{4}: \mathrm{Yb}^{3+}, \mathrm{Er}^{3+} @ \mathrm{PPy}$ samples. The SEM picture shows that the PPy has a distinct cauliflower-like or tumor-like structure. The TEM image in Fig. 5 shows $\mathrm{NaHoF}_{4}: \mathrm{Yb}^{3+}, \mathrm{Er}^{3+} \mathrm{NPs}$ with an average size of $30 \mathrm{~nm}$ and they are well dispersed. The PPy coating of approximately $3 \mathrm{~nm}$ in thickness is attached on the surface of the NPs which is shown by the presence of darker shades on larger disc like nanoplates. This is also shown as a circular edge on the NPs."

- Page 394, the corrected Fig. 5 and corresponding legend is given below.

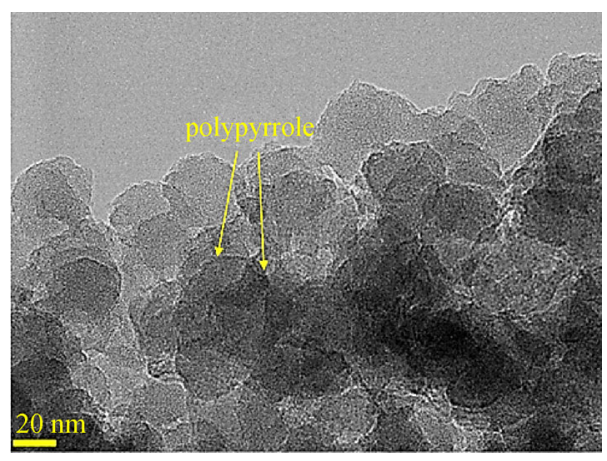

Fig. 5 TEM image of $\mathrm{NaHoF}_{4}: \mathrm{Yb}^{3+}, \mathrm{Er}^{3+} / \mathrm{PPy}$ core-shell NPs.

The authors apologize to the reader. 